\title{
Frequency of Asthma and Atopic Diseases in Inflammatory Bowel Disease and Celiac Disease
}

\author{
Fatma Yavuzyilmaz¹, Sebnem Ozdogan², Nafiye Urganci³ and Merve Kesim Usta3
}

\begin{abstract}
Objective: To compare the frequency of asthma and allergic diseases in patients with inflammatory bowel disease and Celiac disease using international study of asthma and allergies in childhood questionnaire.

Study Design: Cross-sectional, descriptive study.

Place and Duration of Study: Pediatric gastroenterology outpatient clinics and pediatric pulmonology outpatient clinics, from May 2015 to August 2015.

Methodology: Patients aged between 6 and 18 years with the diagnoses of celiac and inflammatory bowel disease were included in the study. After recording the socio-demographic characteristics of all patients, the International study of asthma and allergies in childhood questionnaire was applied and required information collected.

Results: Eighty-three patients (31 males, 52 females) diagnosed with celiac, 42 patients ( 24 males, 18 females) diagnosed with ulcerative colitis, and 28 patients (11 females, 17 males) diagnosed with Crohn's disease were included. No significant difference was found between the groups in terms of the frequency of wheezing, wheezing in the last year, lifelong allergic rhinitis, long-term use of nasal steroids, and history of eczema ( $p>0.05)$. The frequency of atopic dermatitis was significantly higher in the celiac disease group than the other groups.

Conclusion: The frequencies of asthma and atopy are similar in patients with celiac disease and inflammatory bowel disease.
\end{abstract}

Key Words: Asthma, Rhinitis, Eczema, Inflammatory bowel diseases, Celiac disease.

\section{INTRODUCTION}

Asthma is a heterogeneous disease characterised by chronic airway inflammation, which is most commonly seen in children. It is described by variable severity over the time for respiratory symptoms such as wheezing, shortness of breath, chest tightness and cough, and different grades of accompanying expiratory airway obstruction. It has been reported that the prevalence of asthma and allergic diseases are increased in developed countries. 1 There has been an important yet unmet need in terms of interpretation of results and establishment of a relationship between the scientific studies, since no standards have been used to describe allergic diseases and to determine methodology in many epidemiological studies conducted up to now. At this point, the International Study of Asthma and Allergies In Childhood (ISAAC) was suggested as a protocol to facilitate collaboration in the international platform by standardising the epidemiological studies. ${ }^{2}$ While the prevalence of asthma is highly variable worldwide, studies conducted using the ISAAC questionnaire reported that the prevalence of wheezing

Department of Pediatrics 1 / Pediatrics Pulmonology / Gastroenterology3, Sisli Hamidiye Etfal Research and Training Hospital, Istanbul, Turkey

Correspondence: Dr. Sebnem Ozdogan, Department of Pediatrics Pulmonology, Sisli Hamidiye Etfal Research and Training Hospital, Istanbul, 34377, Turkey

E-mail:ozdogan65@hotmail.com

Received: August 15, 2018; Accepted: November 13, 2018 in the last 12 months is in a range between $0.8 \%$ and $32.6 \% .^{3}$

Th2-type immunity, production of IL-4, IL-5 and IgE in response to common environmental antigens plays a role in the development of atopic asthma associated with eosinophilia. However, Th1-type immunity is responsible for many autoimmune diseases such as celiac disease (CD), inflammatory bowel disease (IBD), insulindependent diabetes mellitus and rheumatoid arthritis. Since they develop through different regulatory pathways, it is expected that the frequency of atopic diseases, such as asthma and allergy, should be reduced in autoimmune diseases. However, there are studies that demonstrated increased frequency of asthma and atopic diseases in celiac patients.4-6 Similarly, there are many studies that demonstrated increased frequency of asthma and atopic diseases in IBD patients. ${ }^{7-10}$

Studies that investigated the relationship of celiac disease with asthma and allergic diseases and found a positive correlation suggest that this relationship may be explained by the genetics, and environmental and social common risk factors of these two diseases. ${ }^{4-6,11}$

Similarly, it has been suggested that there is a relationship between asthma and IBD because of the presence of common risk factors such as not being breastfed as a child, antibiotic use during infancy, genetic factors such as SMAD3 that is involved in the pro-inflammatory pathway, and microbiota. ${ }^{12,13}$ 
To the best of the authors' knowledge, there is no published research comparing asthma and atopy frequency in celiac and IBD cases. The aim of this study was to compare the frequency of asthma and atopic diseases using the ISAAC questionnaire in patients with CD and IBD.

\section{METHODOLOGY}

This cross-sectional study was performed between May 2015 and August 2015 at the Pediatric Gastroenterology Outpatient Clinic, after approval from the Ethics Committee of the Hospital. Patients aged between 6 and 18 years with the diagnoses of celiac and inflammatory bowel disease were included in the study. Those who declined to participate in this study, and with missing data, were excluded. A validated ISAAC questionnaire was used in the study, ${ }^{14}$ containing questions relating to asthma, allergic rhino conjunctivitis, and atopic dermatitis. After obtaining informed consent from the subject and/or his/her guardian, the same physician provided the necessary explanations about the questions to the parents and children. The physician imitated the wheezing sound to facilitate better understanding by the families. The allergic salute was described to the families in the questions relating to allergic rhinitis. Blood was collected from the subjects for total IgE and inhalant panel tests.

For specific IgE-inhalant allergens, tree pollens, betula berrucosa, meadow pollens, weed pollens, house dust, dermatophagoides pteronyssinus, dermatophagoides farinae, fungi, yeast and mold and animal epithelia were investigated. Specific IgE inhalant allergens were determined to be normal or high, based on the reference values. The serum total IgE levels were determined to be normal or high, based on the participants' age.

The SPSS 15.0 for Windows software was used for the statistical analysis. In the descriptive statistics, the normally distributed variables were expressed as mean, standard deviation; whereas, non-normal distributed variables were expressed as median and interquartile range, and the categorical variables were expressed as number and percentage. The comparisons for more than two independent groups were performed using the OneWay ANOVA, if the numerical variables met the normal distribution condition; or using Kruskal-Wallis test, if the numerical variables did not meet the normal distribution condition. The subgroup analyses of more than 2 groups were performed using the Tukey's test for parametric tests, and using Mann-Whitney U-test for non-parametric tests, and interpreted using Bonferroni correction. The rate comparisons in the independent groups were performed using the Chi-square analysis. If the conditions were not met, the Monte Carlo simulation was applied. Statistical alpha significance level was considered as $p<0.05$.

\section{RESULTS}

Of the 153 subjects, [70 (46\%) with IBD and 83 (54\%) with $C D$ ] included in the study, $81(53 \%)$ were females and their mean age was $13.21 \pm 3.80$ years. The demographic characteristics of the subjects are shown in Table I. The number of female patients in the group with $C D$ included in the study was higher compared to the other groups, but the mean age, weight, height, age

Table I: Demographic features of the study groups

\begin{tabular}{|c|c|c|c|c|}
\hline & $\begin{array}{c}\text { Celiac } \\
\text { disease }\end{array}$ & $\begin{array}{l}\text { Ulcerative } \\
\text { colitis }\end{array}$ & $\begin{array}{l}\text { Crohn's } \\
\text { disease }\end{array}$ & $\mathrm{p}^{\star *}$ \\
\hline \multicolumn{5}{|l|}{ Gender [n (\%)] } \\
\hline Male & $31(37.3)$ & $24(57.1)$ & $17(60.7)$ & 0.031 \\
\hline Female & $52(62.7)$ & $18(42.9)$ & $11(39.3)$ & \\
\hline \multicolumn{5}{|l|}{ Age } \\
\hline Median (Q1-Q3) & $12(9-16)$ & $15.5(12-17)$ & $15(13.3-16)$ & 0.004 \\
\hline \multicolumn{5}{|l|}{ Weight $(\mathrm{kg})$} \\
\hline Mean $\pm S D$ & $38.7 \pm 15.7$ & $51.9 \pm 18.7$ & $49.2 \pm 12.5$ & $<0.001 \#$ \\
\hline \multicolumn{5}{|l|}{ Weight percentile } \\
\hline$<3 p$ & $26(31.7)$ & $5(11.9)$ & $8(28.6)$ & $0.053^{*}$ \\
\hline$>3 p$ & $56(68.3)$ & $37(88.1)$ & $20(71.4)$ & \\
\hline \multicolumn{5}{|l|}{ Height (cm) } \\
\hline Median (Q1-Q3) & $144(130-160)$ & $162(147.3-171.3)$ & 159 (154.3-166) & $<0.001$ \\
\hline \multicolumn{5}{|l|}{ Height percentile } \\
\hline$<3 p$ & $16(19.5)$ & $4(9.5)$ & $3(10.7)$ & $0.588^{*}$ \\
\hline$>3 p$ & $66(80.5)$ & $38(90.5)$ & $25(89.3)$ & \\
\hline \multicolumn{5}{|l|}{ BMI } \\
\hline Median (Q1-Q3) & $17.6(15.7-20.5)$ & $19.4(16.8-22.6)$ & $19.6(17.1-21.9)$ & 0.050 \\
\hline \multicolumn{5}{|l|}{ BMI groups } \\
\hline Underweight & $20(24.4)$ & $6(14.3)$ & $7(25.0)$ & $0.725^{*}$ \\
\hline Normal & $49(59.8)$ & $26(61.9)$ & $17(60.7)$ & \\
\hline Overweight & $11(13.4)$ & $7(16.7)$ & $3(10.7)$ & \\
\hline \multicolumn{5}{|l|}{ Age at diagnosis } \\
\hline Median (Q1-Q3) & $8(3.5-10)$ & $12(7.8-15.3)$ & $14(11-14.8)$ & $<0.001$ \\
\hline \multicolumn{5}{|l|}{ Follow-up period } \\
\hline Median (Q1-Q3) & $60(12-93)$ & $24(12-60)$ & $24(12-24)$ & 0.006 \\
\hline
\end{tabular}

Table II: Socio-demographic characteristics and the family history of asthma, celiac disease, and inflammatory bowel disease (IBD) in the study groups.

\begin{tabular}{|c|c|c|c|c|}
\hline & $\begin{array}{c}\text { Celiac } \\
\text { disease }\end{array}$ & $\begin{array}{c}\text { Ulcerative } \\
\text { colitis }\end{array}$ & $\begin{array}{l}\text { Crohn's } \\
\text { disease }\end{array}$ & $\mathrm{p}^{\star *}$ \\
\hline $\begin{array}{l}\text { Number of people living } \\
\text { at home } \\
\text { Median (Q1-Q3) }\end{array}$ & $5(4-6)$ & $4(4-5)$ & $4(4-5)$ & $0.077^{\star \star}$ \\
\hline Consanguinity n (\%) & $24(28.9)$ & $11(26.2)$ & $8(28.6)$ & 0.948 \\
\hline Smoke exposure $\mathrm{n}(\%)$ & $43(51.8)$ & $26(61.9)$ & $18(64.3)$ & 0.381 \\
\hline Pets at home $\mathrm{n}(\%)$ & $8(9.6)$ & $3(7.1)$ & $7(25.0)$ & 0.081 \\
\hline $\begin{array}{l}\text { Family history of asthma } \\
\mathrm{n}(\%)\end{array}$ & $19(22.9)$ & $5(11.9)$ & $10(35.7)$ & 0.062 \\
\hline $\begin{array}{l}\text { Family history of AR or } \\
\text { eczema } \mathrm{n}(\%)\end{array}$ & $26(31.3)$ & $7(16.7)$ & $10(35.7)$ & 0.139 \\
\hline $\begin{array}{l}\text { Family history of Celiac/ } \\
\text { IBD n (\%) }\end{array}$ & $3(3.7)$ & $7(16.7)$ & $4(14.3)$ & 0.030 \\
\hline $\begin{array}{l}\text { Hospital admission due } \\
\text { to asthma exacerbation } \\
\mathrm{n}(\%)\end{array}$ & $4(4.8)$ & $3(7,1)$ & $1(3.6)$ & 0.794 \\
\hline
\end{tabular}


Table III: International study of asthma and allergies in childhood (ISAAC) questionnaire.

\begin{tabular}{|c|c|c|c|c|c|c|c|}
\hline & \multicolumn{2}{|c|}{ Celiac disease } & \multicolumn{2}{|c|}{ Ulcerative colitis } & \multicolumn{2}{|c|}{ Crohn's disease } & \multirow[t]{2}{*}{$p^{*}$} \\
\hline & $\mathrm{n}$ & $\%$ & $\mathrm{n}$ & $\%$ & $\mathrm{n}$ & $\%$ & \\
\hline Wheezing (at any time) & 24 & 28.9 & 10 & 23.8 & 7 & 25.0 & 0.808 \\
\hline Wheezing (in the last 12 months) & 16 & 19.3 & 7 & 16.7 & 5 & 17.9 & 0.936 \\
\hline Exercise-induced wheezing & 17 & 20.5 & 11 & 26.2 & 7 & 25.0 & 0.740 \\
\hline Use of asthma medication & 17 & 20.5 & 9 & 21.4 & 6 & 21.4 & 0.990 \\
\hline Night-time coughing & 12 & 14.5 & 8 & 19.0 & 6 & 21.4 & 0.639 \\
\hline Physician-diagnosed asthma & 14 & 16.9 & 7 & 16.7 & 4 & 14.3 & 0.712 \\
\hline Allergic rhinitis & 28 & 33.7 & 17 & 40.5 & 12 & 42.9 & 0.606 \\
\hline Allergic rhino-conjunctivitis & 21 & 25.3 & 13 & 31.0 & 10 & 35.7 & 0.537 \\
\hline Allegic salute & 13 & 15.7 & 2 & 4.8 & 3 & 10.7 & 0.195 \\
\hline Physician-diagnosed allergic rhinitis & 7 & 8.4 & 3 & 7.1 & 1 & 3.6 & 0.842 \\
\hline Nasal steroid use (>2 weeks) & 15 & 18.1 & 5 & 11.9 & 6 & 21.4 & 0.541 \\
\hline H/o atopic dermatitis & 10 & 12.0 & 1 & 2.4 & 0 & 0 & 0.039 \\
\hline Eczema & 20 & 24.1 & 16 & 38.1 & 11 & 39.3 & 0.153 \\
\hline \multicolumn{8}{|l|}{ Total IgE } \\
\hline Normal & 48 & 78.7 & 31 & 77.5 & 22 & 88.0 & 0.541 \\
\hline High & 13 & 21.3 & 9 & 22.5 & 3 & 12.0 & \\
\hline \multicolumn{8}{|l|}{ Inhalant panel } \\
\hline Negative & 50 & 82.0 & 25 & 65.8 & 19 & 79.2 & 0.172 \\
\hline Positive & 11 & 18.0 & 13 & 34.2 & 5 & 20.8 & \\
\hline
\end{tabular}

at diagnosis and duration of diagnosis were significantly lower compared to the subjects with UC and CD. No significant difference was found between the groups in terms of weight percentile, height percentile, mean BMI values and BMI groups.

The sociodemographic characteristics of the subjects included in the study and the family history for asthma, celiac and IBD are shown in Table II. No significant difference was found between the groups in terms of the number of people living at home, consanguinity, smoke exposure, pets at home, family history of asthma, AR and eczema, and number of hospitalisation for asthma. In this study, when family history of celiac in the celiac group and family history of IBD in the IBD group were questioned, the family history IBD in the UC and $C D$ groups was significantly higher compared to the subjects with $C D(p=0.030)$ alone.

The results of the ISAAC questionnaire applied to the subjects are provided in Table III. When wheezing episode at any time, wheezing episodes in the last 12 months, exercise-induced wheezing, previous use of asthma medications, nocturnal cough, physiciandiagnosed asthma, physician-diagnosed AR and longterm (2 weeks or longer) use of nasal steroids were questioned in all subjects by the ISAAC questionnaire, no significant difference was found between the groups $(p>0.05)$. In the questions relating to eczema, the history of atopic dermatitis was statistically significantly higher in the CD group compared to the other groups $(p=0.039)$. No significant difference was found between the groups when frequency of eczema was questioned $(p>0.05)$. No statistically significant difference was found between the total $\operatorname{lgE}$ and inhalant panel values of the subjects $(p>0.05)$.

\section{DISCUSSION}

While autoimmune diseases such as CD and IBD are associated with $\mathrm{T}$ helper cell 1 expression, $\mathrm{T}$ helper cell is involved in the pathophysiology of allergic diseases such as asthma. It has been suggested that both autoimmune and allergic diseases can be seen together due to the common genetic risk factors and environmental factors. 4,11,15 Increased incidence of the diseases other than UC point to common environmental risk factors. 3,16 It is suggested that autoimmune and atopic diseases pose a risk for each other according to studies on large series. 4,17 Based on the results of this study that compared the frequency of asthma and atopy in $C D, U C$ and Crohn's disease, using the ISAAC questionnaire, no significant difference was found between the groups in terms of asthma and atopy symptoms and prevalence. The frequency of atopic dermatitis was significantly higher in CD compared to the other groups.

In this study, the number of female patients in the group with $C D$ was higher compared to the IBD group, which is consistent with the literature.17 The mean age at diagnosis in the celiac group was lower than that of the IBD group, which is also consistent with the literature. ${ }^{18}$ Since the mean age in the celiac group was lower than the other groups, the mean weight and height were also lower in the celiac group. The findings that the weight and height percentiles, mean BMI and BMI groups were similar in all subjects, suggests that there is no significant difference between the groups in terms of growth and developmental retardation. While growth retardation is expected in all CD, UC and Crohn's disease groups, no significant difference was found when the groups were compared with each other.18,19 There are studies in the literature demonstrating that the family history is an 
important risk factor in both CD and IBD.20,21 However, no studies were conducted to compare the frequency of family history in the two patient groups. In the present study, there was a positive family history in both groups, but the rate of family history in the subjects with IBD was significantly higher compared to the subjects with celiac disease.

In literature, majority of the publications support relationship between $C D$ and asthma, allergic rhinitis and atopic dermatitis. ${ }^{4-6,22}$ But, there are a few studies that do not support such relationship. ${ }^{23-24}$

Some of the publications investigating the relationship of IBD with asthma, allergic rhinitis and atopic dermatitis suggest a significant relationship between IBD and asthma and atopy, while others found no relationship. ${ }^{7-10}$ Although there are some publications that investigated the relationship of celiac and IBD with atopy and asthma, there was no study that compared CD and IBD in terms of asthma and atopy. Therefore, there was opportunity to perform a head-to-head comparison of the results of this study. While there was no significant difference between the CD and IBD patients in terms of the frequency of asthma, allergic rhinitis and eczema, the frequency of atopic dermatitis was significantly higher in the CD group.

The strength of this study is that we believe that our study, in which the frequency of asthma and atopy was investigated in children followed-up with the diagnosis of $\mathrm{CD}$ and IBD, provides a significant contribution to the literature. To the best of the authors' knowledge, this is the first study to compare the frequency of asthma and atopy symptoms in CD and IBD. The limitation of our study is the absence of a healthy control group.

\section{CONCLUSION}

Children with $C D, U C$ and Crohn's disease had similar frequency of asthma and atopy.

\section{REFERENCES}

1. Reddel HK, Bateman ED, Becker A, Boulet LP, Cruz AA, Drazen JM, et al. A summary of the new GINA strategy: A roadmap to asthma control. Eur Respir J 2015; 46:622-39.

2. Asher MI, Keil U, Anderson HR, Beasley R, Crane J, Martinez F, et al. International study of asthma and allergies in childhood (ISAAC): Rationale and methods. Eur Respir J 1995; 8:483-91.

3. Lai CK, Beasley R, Crane J, Foliaki S, Shah J, Weiland S, International study of asthma and allergies in childhood phase three sudy group. Global variation in the prevalence and severity of asthma symptoms: Phase three of ine International study of asthma and allergies in childhood (ISAAC). Thorax 2009; 64:476-83.

4. Kero J, Gissler M, Hemminki E, Isolauri E. Could TH1 and TH2 diseases coexist? Evaluation of asthma incidence in children with coeliac disease, type 1 diabetes, or rheumatoid arthritis: A register study. J Allergy Clin Immunol 2001; 108:781-3.

5. Canova C, Pitter G, Ludvigsson JF, Romor P, Zanier L, Zanotti R, et al. Coeliac disease and asthma association in children: The role of antibiotic consumption. Eur Respir J 2015; 46: 115-22.

6. Ludvigsson JF, Hemminki K, Wahlström J, Almqvist C. Celiac disease confers a 1.6-fold increased risk of asthma: A nationwide population-based cohort study. J Allergy and Clin Immunol 2011; 127:1071-3.

7. Kappelman MD, Galanko JA, Porter CQ, Sandler RS. Association of paediatric inflammatory bowel disease with other immune-mediated diseases. Arch Dis Child 2011; 96: 1042-6.

8. Virta LJ, Ashorn M, Kolho KL. Cow's milk allergy, asthma, and pediatric IBD. J Pediatr Gastroenterol Nutr 2013; 56:649-51.

9. Brassard P, Vutcovici M, Ernst P, Patenaude V, Sewitch M, Suissa $S$, et al. Increased incidence of inflammatory bowel disease in Québec residents with airway diseases. Eur Respir J 2015; 45:962-8.

10. Limketkai BN, Sepulveda R, Hing T, Shah ND, Choe M, Limsui D, et al. Prevalence and factors associated with gluten sensitivity in inflammatory bowel disease. Scand J Gastroenterol 2018; 53:147-51.

11. Hemminki K, Li X, Sundquist J, Sundquist K. Subsequent autoimmune or related disease in asthma patients: Clustering of diseases or medical care? Ann Epidemiol 2010; 20:217-22.

12. Kuenzig ME, Barnabe C, Seow CH, Eksteen B, Negron ME, Rezaie A, et al. Asthma is associated with subsequent development of inflammatory bowel disease: A populationbased case-control study. Clin Gastroenterol Hepatol 2017; 15:1405-12.

13. Lees CW, Barrett JC, Parkes M, Satsangi J. New IBD genetics: common pathways with other diseases. Gut 2011; 60:1739-53.

14. Saraçlar Y, Kuyucu S, Tuncer A, Sekerel B, Saçkesen C, Kocabas C. Prevalence of asthmatic phenotypes and bronchial hyper-responsiveness in Turkish schoolchildren: An international study of asthma and allergies in childhood (ISAAC) phase 2 study. Ann Allergy Asthma Immunol 2003; 91:477-84.

15. Simpson CR, Anderson WJ, Helms PJ, Taylor MW, Watson L, Prescott GJ, et al. Coincidence of immune-mediated diseases driven by Th1 and Th2 subsets suggests a common aetiology. A population-based study using computerized general practice data. Clin Exp Allergy 2002; 32:37-42.

16. Molodecky NA, Soon IS, Rabi DM, Ghali WA, Ferris M, Chernoff G, et al. Increasing incidence and prevalence of the inflammatory bowel diseases with time, based on systematic review. Gastroenterology 2012; 142:46-54.

17. Senapati S, Sood A, Midha V, Sood N, Sharma S, Kumar L, et al. Shared and unique common genetic determinants between pediatric and adult celiac disease. BMC Med Genomics 2016; 9:44.

18. Heyman MB, Kirschner BS, Gold BD, Ferry G, Baldassano R, Cohen SA, et al. Children with early-onset inflammatory bowel disease (IBD): Analysis of a pediatric IBD consortium registry. $J$ Pediatr 2005; 146:35-40.

19. Holtmeier W, Caspary WF. Celiac disease. Orphanet J Rare Dis 2006; 1:3.

20. Hemminki K, Li X, Sundquist K, Sundquist J. Familial association of inflammatory bowel diseases with other autoimmune and related diseases. Am J Gastroenterol 2010; 105:139-47. 
21. Lionetti E, Castellaneta S, Pulvirenti A, Tonutti E, Francavilla R, Fasano A, et al. Prevalence and natural history of potential celiac disease in at-family-risk infants prospectively investigated from birth. J Pediatr 2012; 161:908-14.

22. Ellul $P$, Vassallo $M$, Montefort $S$. Association of asthma and allergic rhinitis with celiac disease. Indian J Gastroenterol 2005; 24:270-1.
23. Greco L, De Seta L, D'Adamo G, Baldassarre C, Mayer M, Siani $\mathrm{P}$, et al. Atopy and coeliac disease: Bias or true relation? Acta Paediatr Scand 1990; 79:670-4.

24. Ciacci C, Cavallaro R, lovino P, Sabbatini F, Palumbo A, Amoruso $D$, et al. Allergy prevalence in adult celiac disease. J Allergy Clin Immunol 2004; 113:1199-203.

......... 